\title{
Modelling the influence of age of steel fibre reinforced self-compacting concrete on its compressive behaviour
}

\author{
V. M. C. F. Cunha · J. A. O. Barros · J. Sena-Cruz
}

Received: 10 April 2006/ Accepted: 8 May 2007/Published online: 7 June 2007

(C) RILEM 2007

\begin{abstract}
Steel fibre reinforced self-compacting concrete (SFRSCC) can combine the benefits of self-consolidating concrete technology with those derived from adding steel fibres to quasi-brittle cement based materials. In a recent applied research project joining pre-casting industry, private and public research institutions, a method was developed to design cost-competitive SFRSCC of rheological and mechanical properties required for the prefabrication of SFRSCC façade panels. To assure safe demoulding process of the panels, the influence of the concrete age on the compression behaviour of the SFRSCC should be known. For this purpose, series of tests with specimens of $12 \mathrm{~h}$ to 28 days were tested in order to analyze the age influence on the compressive strength, strain at peak stress, Young's modulus, and compressive volumetric fracture energy. The experimental program was divided in two groups of test series, one with SFRSCC of a volumetric fibre percentage of $0.38 \%$ and the other with $0.57 \%$. To apply the obtained data in the design and numerical analysis framework, the influence of the age on these SFRSCC properties was modelled. This work describes the carried out experimental program,
\end{abstract}

V. M. C. F. Cunha $(\bowtie) \cdot$ J. A. O. Barros · J. Sena-Cruz Department of Civil Engineering, University of Minho, Campus Azurem, Guimaraes, Portugal

e-mail: vcunha@civil.uminho.pt presents and analyzes the obtained results, and provides the derived analytical expressions.

Résumé Le béton auto-plaçant avec fibres métalliques (SFRSCC) peut combiner les avantages de la technologie de l'auto-consolidation du béton avec ceux qui résultent de l'addition de fibres métalliques aux matériaux fragiles. Dans un récent projet de recherche impliquant l'industrie de préfabrication et des institutions de recherches publiques et privées, on a développé une méthode pour obtenir du SFRSCC de coût compétitif, avec des caractéristiques rhéologiques et mécaniques requises pour la préfabrication de panneaux de façade en SFRSCC.

Afin de garantir la sécurité du processus de décoffrage des panneaux, il faut connaitre l'influence de l'âge sur le comportement à la compression du SFRSCC. Ainsi, on a fait des essais avec des éprouvettes âgées de 12 heures jusqu'à 28 jours, en vue d'analyser l'influence de l'âge sur la résistance à la compression, la déformation correspondant au pic en compression, le module d'Young et l'énergie volumétrique en compression. Le programme expérimental a été divisé en deux séries d'essais portant sur des mélanges de SFRSCC de pourcentage de fibres distinct de 0,38\% et 0,57\% en volume. Pour appliquer les résultats obtenus dans ce projet à la conception et à l'analyse numérique, l'influence de l'âge du SFRSCC sur les caractéristiques auparavant citées a été simulée. Ce travail décrit le programme 
expérimental réalisé. Il présente et analyse les résultats obtenus et propose des expressions analytiques.

Keywords Self-compacting concrete $\cdot$ Steel fibre Compressive behaviour $\cdot$ Early age $\cdot$ Stress-strain relationship · Analytical model

\section{Introduction}

The use of steel fibre reinforced self-compacting concrete, SFRSCC, probably, will swiftly increase in the next years, since this composite material introduces several advantages on the concrete technology. In fact, the partial or total replacement of the conventional bar reinforcement by discrete fibres optimizes the construction process. The assembly of the reinforcement bars in the construction of concrete structures has a significant economical impact on the cost of this type of constructions, due to the manlabour time that it requires. In modern societies, the cost of man-labour is significant, from which diminishing the man-labour will decrease the construction costs. For this reason, SFRSCC is a very promising construction material with high potential of application, mainly in the cases where fibres can replace conventional reinforcement. At the present time, however, the SFRSCC technology is not yet fully developed and controlled. Moreover, the mechanical behaviour of SFRSCC material is still not clearly understood. The energy absorption capacity and the impact strength of cement based materials are the properties most benefited by the addition of fibres to concrete. A detailed description of the benefits provided by the fibre addition to concrete can be found elsewhere [1-3]. The fibre addition might also improve the shear resistance [4], as well as the fire resistance of cement-based materials [5]. Recently, Grünewald [6] compared the mechanical behaviour of conventionally vibrated concrete that is reinforced with steel fibres. In this paper, the latter will be referred to as fibre reinforced concrete (FRC). Grünewald carried out beam bending tests and fibre pull-out tests, and concluded that the flexural and fibre pullout behaviour were much better in the SFRSCC.

Scarce research is available on the modelling of the compression behaviour of SFRSCC, specially the influence of the SFRSCC age in this behaviour. A good knowledge of the stress-strain relationship at early ages plays an important role in the determination of the time for the removal of shoring. This is a main concern in the pre-cast industry, since demoulding the elements as soon as possible is an important requirement in terms of production profitability. To assure safe demoulding process, the influence of the concrete age on the compression behaviour of the SFRSCC should be known.

The stress-strain relationship, $\sigma_{c}-\varepsilon_{c}$, representing the behaviour of a material under uniaxial compression, is an important material characteristic of concrete. However, due to various influencing factors and different experimental conditions, distinct $\sigma_{c}-\varepsilon_{c}$ relationships are available. Most model equations used presently have been developed for 28-days concrete age and for plain [7, 8] and FRC [9, 10]. According to the knowledge of the authors of the present article, there is not a formulation for predicting the influence of the SFRSCC age on the $\sigma_{c}-\varepsilon_{c}$ expression that simulates its compressive behaviour.

This work contributes for fulfilling this gap. For this purpose, uniaxial compression tests were carried out. The influence of the concrete age and fibre content on the behaviour of SFRSCC was analysed. The details of the tests are described, and the obtained results are discussed. Stress-strain laws are proposed to model the behaviour of the SFRSCC since the early ages. Additionally, expressions derived from fitting the experimental obtained results are proposed to predict the principal mechanical properties of SFRSCC in uniaxial compression.

\section{Experimental program}

The experimental program presented in this work was defined with the intention of evaluating the influence of the fibre content and concrete age on the uniaxial behaviour of SFRSCC. For this purpose, two series of distinct fibre contents were used: the first one with $30 \mathrm{~kg} / \mathrm{m}^{3}$ (fibre volume percentage, $V_{f}$, of $0.38 \%$ ) is denominated as $C f 30$ series and, the other, with $45 \mathrm{~kg} / \mathrm{m}^{3}\left(V_{f}=0.57 \%\right)$ designated as $C f 45$ series. Each one of these series was composed by sub-series that were tested at 12 and $24 \mathrm{~h}, 3,7$ and 28 days. The specimens of each sub-series were covered by moistened burlap. For the $C f 30$ series the curing tempera-ture was about $10^{\circ} \mathrm{C}$, whereas for the $C f 45$ was $20^{\circ} \mathrm{C}$. 
The stress-strain relationship was obtained as the direct result of the compression tests. Additionally, the following main mechanical properties of the SFRSCC were also determined: compressive strength, $f_{c m}$; elasticity modulus, $E_{c i}$; strain at peak stress, $\varepsilon_{c 1}$ and the volumetric energy dissipated, $G_{c}$.

\subsection{Concrete mixture}

The materials used in the composition of the SFRSCC, were: cement (C) CEM-I-42.5R, limestone filler (LF), super-plasticizer (SP) of third generation based on poly-carboxilates (Glenium ${ }^{\circledR}$ 77SCC), water $(\mathrm{W})$, three types of aggregates (fine river sand (FS), coarse river sand (CS) and crushed granite 5$12 \mathrm{~mm}(\mathrm{CA}))$ and DRAMIX ${ }^{\circledR}$ RC-80/60-BN hookended steel fibres. The adopted fibre had a length $\left(l_{f}\right)$ of $60 \mathrm{~mm}$, a $0.75 \mathrm{~mm}$ diameter $\left(d_{f}\right)$, an aspect ratio $l_{f} /$ $d_{f}$ of 80 and a yield stress of 1,100 MPa.

In a previous research [11] a method to achieve the optimum SFRSCC composition was developed, which is based on the three following steps: (1) the proportions of the constituent materials of the binder paste were defined; (2) the proportions of each aggregate on the final solid skeleton were determined; (3) binder paste and solid skeleton were mixed in different proportions until self-compacting requirements in terms of spread ability, correct flow velocity, filling ability, blockage and segregation resistance were assured.

Table 1 includes the composition that has best fitted self-compacting requirements for the two adopted contents of fibres $(C f), 30$ and $45 \mathrm{~kg} / \mathrm{m}^{3}$. Remark that, in Table 1, WS is the water necessary to saturate the aggregates and $\mathrm{W} / \mathrm{C}$ is the water/cement ratio. The parcel WS was not used to compute the ratio $\mathrm{W} / \mathrm{C}$. The water used to calculate the $\mathrm{W} / \mathrm{C}$ ratio includes the water parcel of the super-plasticizer. The latter has $20 \%$ solids content and a specific weight approximately of $1.05 \mathrm{~g} / \mathrm{cm}^{3}$.
No sign of segregation was detected, a total spread over $700 \mathrm{~mm}$ was measured and the mixture showed good homogeneity and cohesion, even when flowing through the small orifice of the Abrams cone (when testing, Abrams cone was always used in the inverted position).

\subsection{Test set-up}

The compression tests to obtain the elasticity modulus and the stress-strain relationship were carried out in a servo-controlled equipment of $3,000 \mathrm{kN}$ maximum load capacity. Six cylindrical specimens, with $150 \mathrm{~mm}$ diameter and $300 \mathrm{~mm}$ height, were used for each series.

\subsubsection{Elasticity modulus}

The determination of the elasticity modulus was performed according to the LNEC E397 Portuguese standard [12]. According to this specification, a test should be carried out under force control over a certain number of cycles. A test ends when the strain difference, between two consecutive load cycles, does not exceed $1 \times 10^{-5}$. In the initial phase of the test, a compression stress level of $0.5 \mathrm{MPa}, \sigma_{b}$, is applied, and the corresponding strain is measured, $\varepsilon_{b}$. The stress is then increased at a stress ratio of $0.2 \mathrm{MPa} / \mathrm{s}$ until a stress level $\sigma_{a}=f_{c} / 3$ is attained, where $f_{c}$ is the compressive strength, previously assessed in a direct compression test. The stress $\sigma_{a}$ is maintained for $90 \mathrm{~s}$, and in the last $30 \mathrm{~s}$ of this period, the strains are recorded, $\varepsilon_{a}$. After this period, the load is decreased at a stress ratio of $0.2 \mathrm{MPa} / \mathrm{s}$ until a stress level $\sigma_{b}$. This stress level is maintained for a period of $90 \mathrm{~s}$, and in the last $30 \mathrm{~s}$ of this period, the strains are recorded. The elasticity modulus is the average of the $E_{c, n}$ values obtained in each cycle:
Table 1 Final composition for $1 \mathrm{~m}^{3}$ of SFRSCC

\begin{tabular}{llllll}
\hline$C f(\mathrm{~kg})$ & Paste/total volume $(\%)$ & Cement $(\mathrm{kg})$ & $\mathrm{LF}(\mathrm{kg})$ & $\mathrm{W}\left(\mathrm{dm}^{3}\right)$ & $\mathrm{WS}\left(\mathrm{dm}^{3}\right)$ \\
\hline 30 & 0.34 & 359.4 & 312.2 & 96.9 & 64.7 \\
45 & 0.38 & 401.7 & 344.3 & 108.4 & 60.8 \\
$C f(\mathrm{~kg})$ & $\mathrm{SP}\left(\mathrm{dm}^{3}\right)$ & FS $(\mathrm{kg})$ & $\mathrm{CS}(\mathrm{kg})$ & $\mathrm{CA}(\mathrm{kg})$ & $\mathrm{W} / \mathrm{C}$ \\
30 & 6.9 & 108.2 & 709.4 & 665.2 & 0.29 \\
45 & 7.6 & 101.7 & 666.4 & 624.8 & 0.29 \\
\hline
\end{tabular}


$E_{c, n}=\frac{\Delta \sigma_{n}}{\Delta \varepsilon_{n}}=\frac{\sigma_{a, n}-\sigma_{b, n}}{\varepsilon_{a, n}-\varepsilon_{b, n}}$

where $\sigma_{a, n}$ and $\sigma_{b, n}$ are the average of the two stress limits of the $n^{\text {th }}$ cycle, $\varepsilon_{a, n}$ and $\varepsilon_{b, n}$ are the correspondent strains. The axial strain was evaluated from the displacements recorded in three linear voltage displacement transducers, $L V D T$ 's, placed according to the scheme represented in Fig. 1. The distance between the two rings was $100 \mathrm{~mm}$ [12]. The two rings were positioned at equal distance from the mid height of the specimen.

\subsubsection{Stress-strain curve}

The entire stress-strain curve, $\sigma_{c}-\varepsilon_{c}$, can only be obtained when stable tests are performed, which requires highly stiff equipment of sophisticated closed-loop servo control devices [13]. The used test rig had these features and the tests were carried out under displacement control.

During the test, the specimen axial strain was obtained from the relative displacement of the machine load platens. For this purpose, three linear voltage displacement transducers, LVDT's, were disposed around the test sample forming an angle of $120^{\circ}$ between consecutive LVDT's, see Fig. 2. This test configuration avoids that the deformation of the test equipment is added to the displacements read by the LVDT's. This arrangement of the transducers also allows that the specimen deformation in the longitudinal axis can be computed dividing the average readouts of the three transducers by the initial measured height of the specimen.
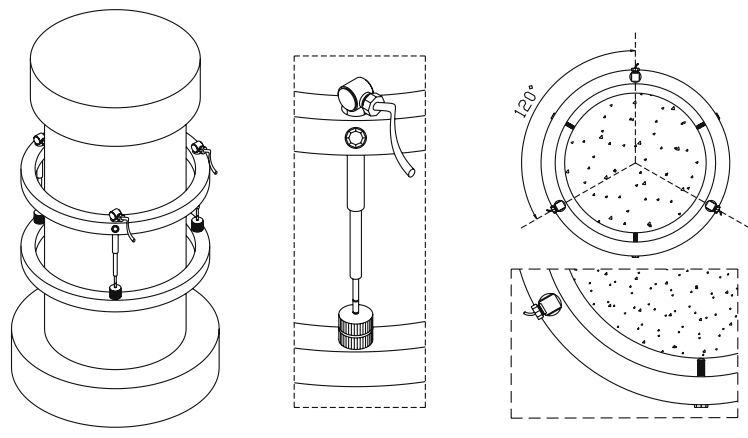

Fig. 1 Setup of the compression test to obtain the elasticity modulus

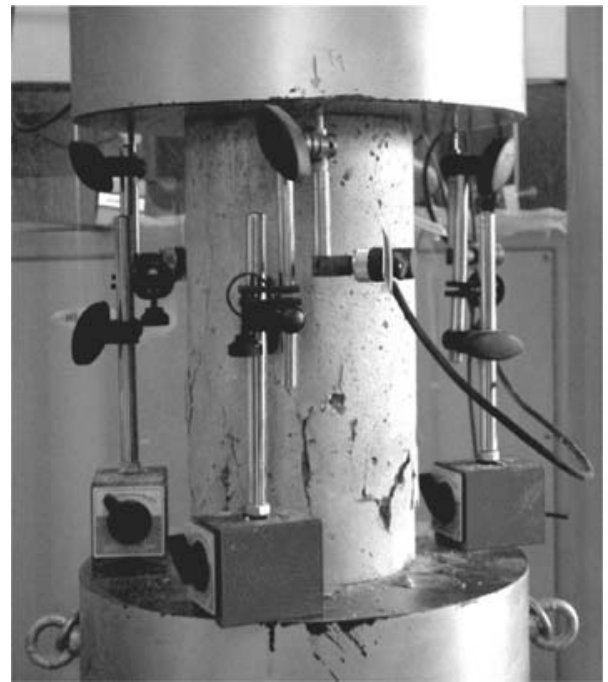

Fig. 2 Setup of the compression test to obtain the stress-strain curve

\section{Experimental results}

\subsection{Stress-strain relationship}

The average stress-strain curves, $\sigma_{c}-\varepsilon_{c}$, for the $C f 30$ and $C f 45$ series are represented in Fig. $3 a$ and b, respectively.

A larger non-linear branch can be observed in the prepeak phase of the specimens of 12 and $24 \mathrm{~h}$. In fact, a pronounced nonlinear behaviour is observed in the prepeak phase due to the aggregates-paste weak bond at this age. During the specimen loading procedure, the porous structure of the aggregate/paste interface is gradually converted into discontinuous microcracks and, finally, into continuous cracks. Since the stiffness of the paste is relatively low at these stages, this damage evolution process is much more stable than in older specimens. Consequently, smoother residual strength decay has occurred in the softening phase of the $12 \mathrm{~h}$ specimens. At this age, the energy dissipated by the pullout of the fibres after crack initiation is only a small part of the energy that fibre pullout can dissipate in concretes of older ages, since the bond strength and the stiffness of the fibreconcrete interface is still relatively low at $12 \mathrm{~h}$. Throughout the concrete aging, the interface and the paste become stiffer, resulting in a $\sigma_{c}-\varepsilon_{c}$ linear relationship of higher amplitude in the pre-peak phase. This stiffening and strengthening gaining process leads to more brittle responses in the post-peak phase. 

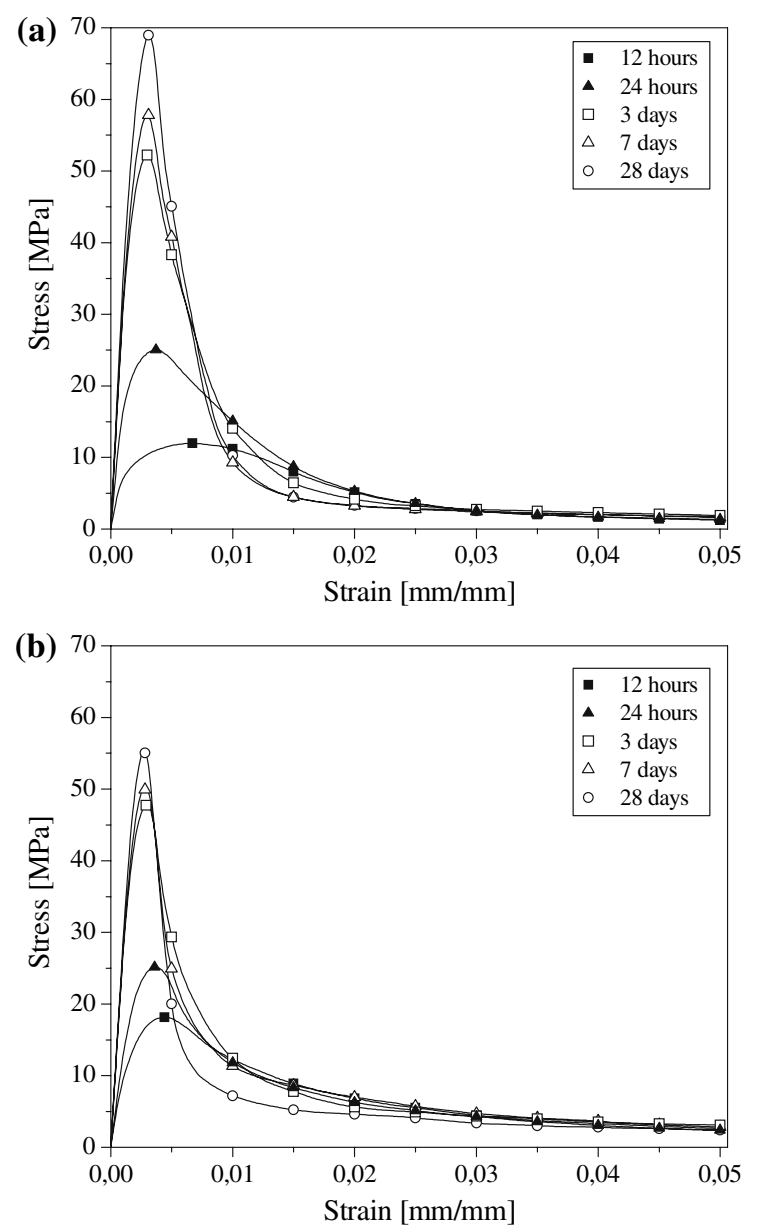

Fig. 3 Average stress-strain relationships for the series: (a) $C f 30$ and (b) Cf45

As the volume of fibre increases, there is a higher likelihood that when a crack occurs it will be bridged by a fibre. Thus, the energy adsorption should have increased as the fibre content was increased. However, this did not occur in the present research, which can be seen by the decrease of the compressive strength from series $C f 30$ to $C f 45$. It is possible that the decrease was caused by a reduction in the fiberconcrete bond strength, and consequently the energy dissipated in the fiber pull-put process was also decreased. The decrease of the compressive strength from series $C f 30$ to $C f 45$ might be justified by the higher LF percentage, as well as the lower content of coarse aggregate in the Cf45 mix composition (see Table 1). Previous research [11] showed that paste strength decreases with the increase of LF content.
Table 2 Average values of the compressive strength

\begin{tabular}{llllll}
\hline Age & Cf30 & & & \multicolumn{2}{l}{ Cf45 } \\
\cline { 2 - 3 } \cline { 5 - 6 } & $f_{c m}[\mathrm{MPa}]$ & $\mathrm{CoV}[\%]$ & & $f_{c m}[\mathrm{MPa}]$ & $\mathrm{CoV}[\%]$ \\
\hline $12 \mathrm{~h}$ & 12.3 & 9.95 & & 17.6 & 1.63 \\
$24 \mathrm{~h}$ & 24.7 & 8.38 & & 25.3 & 1.24 \\
3 days & 52.3 & 1.90 & & 47.9 & 1.10 \\
7 days & 58.1 & 4.32 & & 51.0 & 2.61 \\
28 days & 69.7 & 1.73 & 56.2 & 2.15 \\
\hline
\end{tabular}

3.2 Age influence on the mechanical properties

\subsubsection{Compressive strength}

Table 2 includes the average values of the compressive strength, $f_{c m}$, and the correspondent coefficients of variation, CoV. As expected, for both series, the $f_{c m}$ increases with age. Up to $24 \mathrm{~h}$ the compressive strength of $C f 45$ was higher than that for $C f 30$. However, after this age the $f_{c m}$ of $C f 30$ had a strengthening much more pronounced with time than the one measured in $C f 45$.

This difference on the compressive strength observed for the $C f 30$ and $C f 45$ series may be due to the influence of the limestone filler and curing temperature on the hydration process of the Portland cement. Before advancing with a possible explanation for these results, it is important to clarify that by logistic motives, the curing temperatures were distinct for each series. For the $C f 30$ series the curing temperature was about $10^{\circ} \mathrm{C}$, whereas for the $C f 45$ was $20^{\circ} \mathrm{C}$.

The strength growing with age is significantly influenced by the curing temperature [14]. The higher compressive strengths for the $C f 45$ series at the younger ages may be due to the higher curing temperature [14] and also to the higher content of filler. Although the filler material has often been considered to be inert, recent experimental research [15] showed that limestone filler influences the hydration process. The very small particles of filler favour the rapid growth hydration, the hydrated crystals build more easily the connection between particles, and the crystalline microstructure is established more rapidly, resulting on higher compressive strengths at early ages. For the 3, 7 and 28 days, the compressive strength was higher in the $C f 30$ series, due to the strength cross-over effect observed for a lower curing temperature, e.g. as smaller the curing temperature, the higher the 
compressive strength at old ages and vice-versa [14]. This effect may also been outsized by the higher limestone filler content for the $C f 45$ series.

\subsubsection{Elasticity modulus}

The average values of the elasticity modulus, $E_{c i}$, and the correspondent coefficients of variation, $\mathrm{CoV}$, are indicated in Table 3. The $E_{c i}$ increased with age for both series. The $E_{c i}$ had a similar variation with age as $f_{c m}$. However, for $C f 30$ the $f_{c m}$ value increased between 7 and 28 days, while the $E_{c i}$ of the series Cf 30 had a marginal increment in this period. After the age of three days, the $E_{c i}$ of the $C f 45$ series, had an increment of only $3 \mathrm{GPa}$. These results point out that the stiffness of both SFRSCC is at the ages of 3 days is approximately $90 \%$ of the stiffness at 28 days, due to the high matrix compacity of these concretes. The difference between the values of elasticity modulus of $C f 30$ and $C f 45$ series may be due to the influence of the curing temperature and content of limestone filler, as previously explained.

\subsubsection{Strain at peak stress}

The average values of the strain at peak stress, $\varepsilon_{c 1}$, and the correspondent coefficients of variation, $\mathrm{CoV}$, are included in Table 4. Due to the increase of concrete

Table 3 Average values of the elasticity modulus

\begin{tabular}{llllll}
\hline Age & \multicolumn{2}{l}{ Cf30 } & & Cf45 \\
\cline { 2 - 3 } \cline { 5 - 6 } & $\mathrm{E}_{\mathrm{ci}}[\mathrm{GPa}]$ & $\mathrm{CoV}[\%]$ & & $\mathrm{E}_{\mathrm{ci}}[\mathrm{GPa}]$ & $\mathrm{CoV}[\%]$ \\
\hline $12 \mathrm{~h}$ & 13.6 & 17.86 & & 18.8 & 7.10 \\
$24 \mathrm{~h}$ & 25.3 & 4.96 & & 22.4 & 5.83 \\
3 days & 37.1 & 4.31 & & 31.4 & 2.04 \\
7 days & 40.4 & 0.78 & & 31.9 & 2.14 \\
28 days & 41.5 & 2.31 & & 34.5 & 4.33 \\
\hline
\end{tabular}

Table 4 Average values of the strain at peak stress

\begin{tabular}{llllll}
\hline Age & \multicolumn{2}{c}{$\mathrm{Cf30}$} & & $\mathrm{Cf45}$ \\
\cline { 2 - 3 } \cline { 5 - 6 } & $\varepsilon_{\mathrm{c} 1}[\%]$ & $\mathrm{CoV}[\%]$ & & $\varepsilon_{\mathrm{c} 1}[\%]$ & $\mathrm{CoV}[\%]$ \\
\hline $2 \mathrm{~h}$ & 0.67 & 28.90 & & 0.47 & 10.25 \\
$24 \mathrm{~h}$ & 0.39 & 7.84 & & 0.37 & 5.27 \\
3 days & 0.30 & 3.99 & & 0.30 & 5.77 \\
7 days & 0.31 & 5.14 & & 0.29 & 9.55 \\
28 days & 0.31 & 6.28 & & 0.28 & 5.69 \\
\hline
\end{tabular}

stiffness, $\varepsilon_{c 1}$ decreased with the age for both series. Since the increase of $E_{c i}$ after 3 days was not significant, the variation of $\varepsilon_{c 1}$ was small after this age.

The $\varepsilon_{c 1}$ values at the age of 28 days for the both series are of about 0.003 . Other authors obtained similar values of $\varepsilon_{c 1}$ for current SFRC [10, 13, 16]. This value is higher than the value of 0.0022 , proposed by the Model code 1990 [8] for plain concrete. On the other hand, the EN 1992-1-1 standard [17] suggests different values of $\varepsilon_{c 1}$ for the distinct concrete strength classes. For the average compressive strength of the Cf3O series, the value suggested by this standard is 0.0026 , whereas for the average strength of $C f 45$ series the value proposed is 0.00245 . The difference between these values and the ones obtained experimentally is due to the effect of the fibres bridging the cracks that are formed before the peak load.

\subsubsection{Energy dissipated under compression}

The energy dissipated under compression per concrete unit volume, $G_{c}$, was calculated as the area under the stress-strain curve, $\sigma_{c}-\varepsilon_{c}$, i.e.:

$G_{c}=\int_{0}^{\varepsilon_{u}} \sigma_{c} \cdot d \varepsilon$

The $G_{c}$ value was always determined until ultimate strain, $\varepsilon_{u}$, of 0.05 , to which the residual strength is a small percentage of the specimen compressive strength.

Table 5 includes the average values of $G_{c}$ and the corresponding coefficients of variation, $\mathrm{CoV}$. In general, the concrete energy absorption increased with age. When compared with the previous analysed material parameters, the values of the coefficients of variation are quite high.

Table 5 Average values of the energy dissipated under compression

\begin{tabular}{|c|c|c|c|c|}
\hline \multirow[t]{2}{*}{ Age } & \multicolumn{2}{|l|}{ Cf30 } & \multicolumn{2}{|l|}{ Cf45 } \\
\hline & $\mathrm{G}_{\mathrm{c}}\left[\mathrm{N} / \mathrm{mm}^{2}\right]$ & $\mathrm{CoV}[\%]$ & $\mathrm{G}_{\mathrm{c}}\left[\mathrm{N} / \mathrm{mm}^{2}\right]$ & $\mathrm{CoV}[\%]$ \\
\hline $12 \mathrm{~h}$ & 0.26 & 18.03 & 0.33 & 12.35 \\
\hline $24 \mathrm{~h}$ & 0.36 & 13.13 & 0.38 & 12.01 \\
\hline 3 days & 0.48 & 12.70 & 0.46 & 19.73 \\
\hline 7 days & 0.44 & 14.84 & 0.47 & 34.37 \\
\hline 28 days & 0.49 & 10.31 & 0.39 & 18.77 \\
\hline
\end{tabular}


The major part of the energy is released in the softening phase that is too dependent on the fibre reinforcement mechanisms provided by fibres crossing the cracks. The efficiency of those mechanisms depend considerably on the fibre bond length and fibre orientation towards the cracks they bridge, whose homogeneity can not be assumed between two, apparently, equal batches. This justifies the high $\mathrm{CoV}$ values attained for the $G_{c}$. The differences between the energy dissipated on the $C f 30$ and $C f 45$ series is discussed in a posterior section.

\subsection{Compressive toughness}

The concrete toughness represents the ability of material to absorb energy. A convenient way to quantify the increase of toughness provided by the fibre reinforcement is to define a toughness index, TI, which is the ratio between the energy dissipated by the fibre reinforced concrete, up to a given strain limit, and the energy dissipated by its correspondent plain concrete [10]. The toughness was computed using Eq. 2, until to levels of strain, 0.001 and 0.005 . The stress-strain relationship for the plain concrete proposed by the Model Code 1990 [8] was used to determine the toughness of this concrete. In order to define the stress-strain relationship, the values of $f_{c m}$, $E_{c}$ must be known. For this purpose, the values of Tables 2 and 3 were used for both $C f 30$ and $C f 45$ series. The $\varepsilon_{c 1}$ value for the plain concrete was always assumed 0.0022 in agreement with Model Code 1990.

Figure 4 represents the variation of TI parameter with the reinforcement index, $R I=V_{f} \times l_{f} / d_{f}$. Figure $4 \mathrm{a}$ shows the TI, calculated until a deformation of 0.01 . The value of TI for the $C f 30$ series $(\mathrm{RI}=0.33)$, is in the range $[2,2.75]$, meaning that the energy absorption of this concrete is $2-2.75$ times higher than the one absorbed by the corresponding plain concrete, until a strain of 0.01 . On the other hand, for $C f 45$ series (RI $=0.47$ ), apart from the series of $12 \mathrm{~h}$, the values of TI were lower than the ones of $C f 30$ series. In Fig. $4 \mathrm{~b}$ the TI was calculated up to a strain of 0.05 . The values of TI when compared to those obtained until a deformation of 0.01 , increased substantially. The toughness index, for deformations up to 0.05 , increased with the reinforcement index. The only exception was the series with 28 days.
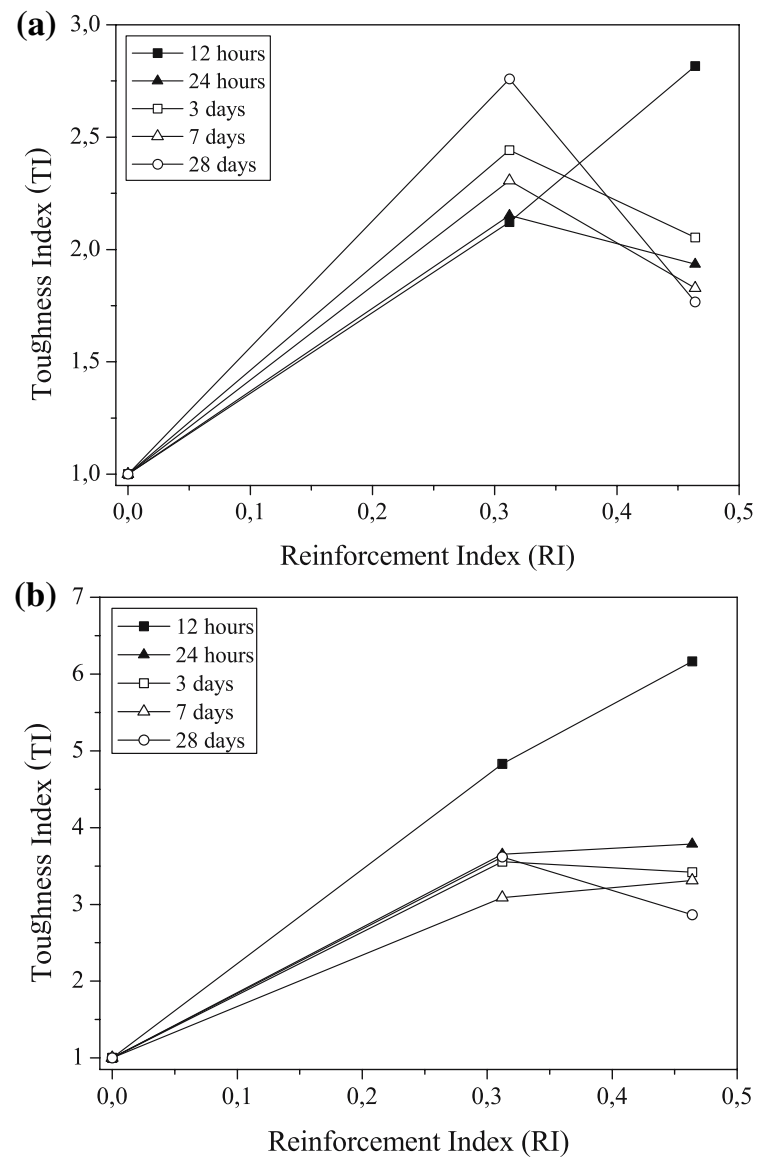

Fig. 4 Variation of the toughness index with the reinforcement index up to a strain: (a) 0.01 and (b) 0.05

The toughness of a fibre reinforced concrete is significantly influenced by the reinforcement mechanisms mobilized during the fibre pullout. In pullout tests with hooked-end fibres (DRAMIX 80/60) into selfcompacting concrete, Grünewald [6] observed that the fibre-matrix bond strength and the pullout force to straighten the fibre hooked ends increased with the matrix strength, but the influence of the matrix performance was more pronounced on the bond strength.

Taking these observations into account, the decrease of TI with the increase of the fibre content for a deformation of 0.01 and for the specimens with $24 \mathrm{~h}, 3,7$ and 28 days (see Fig. 4a), might be justified by the fact that, up to this level of deformation, the strength of the matrix is lower for the $C f 45$ series, resulting lower fibrematrix bond strength. Since the fibre-matrix bond strength plays an important role on the fibre pullout reinforcement mechanisms for smaller fibre slips, an 
inferior dissipated energy is expected for the aforementioned specimens. The compressive strength argument also justifies the greater energy absorption capacity of $12 \mathrm{~h}$ specimens of $C f 45$ series, for a deformation of 0.01 (see Fig. 4a and Table 2). The influence of the SFRSCC compressive strength on the energy absorption capacity for a deformation level of 0.05 is also similar to that observed for a deformation level of 0.01 , but not so pronounced (see Fig. 4). In fact, for a deformation level of 0.05 , the fibre hooked-end anchorage is mobilized, being its contribution to the energy dissipated on the pullout process not so influenced by the strength of the matrix, which justifies the similar TI values in both $C f 30$ and $C f 45$ series for the specimens with 24 h, 3 and 7 days. However, since compressive strength of specimens with $12 \mathrm{~h}$ and 28 days were significantly distinct in $C f 30$ and $C f 45$ series, the corresponding TI values had also considerable different values, and followed the compressive strength argument (see Fig. 4b).

\section{Analytical expressions}

In this section, analytical expressions are proposed to predict the evolution with the age of the most significant properties of the SFRSCC in compression. For this purpose, a non-linear fitting method was used and a statistical treatment of the experimental data was done [18].

\subsection{Mechanical properties}

\subsubsection{Compressive strength}

To estimate the compressive strength of plain concrete at various ages, $f_{c m}(t)$, the Model code 1990 (MC90) [8] suggests the following expression:

$f_{c m}(t)=f_{c m}(28) \cdot \exp \left\{a\left[1-\left(\frac{28}{t}\right)^{b}\right]\right\}$

where $f_{c m}(28)$ is the mean compressive strength value at 28 days, and $a, b$ are two dimensionless parameters, that, for plain concrete, MC90 proposes $a=0.2$, in case of using rapid hardening high strength cements, and a constant value of 0.5 for parameter $b$.
Using the $f_{c m}(28)$ values obtained in the tested SFRSCC series, the $f_{c m}(t) / f_{c m}(28)$ function, evaluated according to the MC90 proposal, is depicted in Fig. 5. In spite of the fact that the obtained correlation factor, $R^{2}$, is quite high, the compressive strength predicted by Eq. 3 at the ages of 3 and 7 days is underestimated, particularly, for the series with $45 \mathrm{~kg} / \mathrm{m}^{3}$ of steel fibres.

Using the non-linear fitting method, the values of parameters $a$ and $b$ of Eq. 3 were determined in order to improve its capability of simulating the age effect on the compressive strength of the developed SFRSCC. The degree of the simulation of the fitted curve increased considerably, especially at the ages of 3 and 7 days. The values of the fitted curve parameters, as well as, the value of $R^{2}$ are included in Fig. 5.

\subsubsection{Elasticity modulus}

In resemblance to the compressive strength, MC90 [8] proposes the following expression:

$E_{c i}(t)=E_{c i}(28) \cdot\left\{\exp \left[a\left(1-\left(\frac{28}{t}\right)^{b}\right)\right]\right\}^{c}$

to determine the elasticity modulus at an age of $t$ days, $E_{c i}(t)$, where $E_{c i}(28)$ is the elasticity modulus at an age of 28 days, and $a, b$ and $c$ are dimensionless parameters. The MC90 indicates for plain concrete $c=0.5$, whereas the values of $a$ and $b$ are the same ones as those proposed for the Eq. 3 .

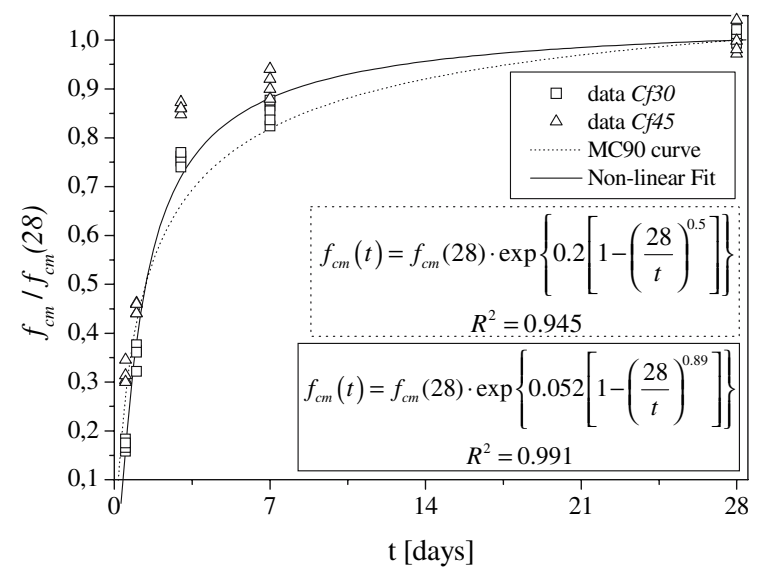

Fig. 5 Simulation of the age influence on the concrete compressive strength 
Using the $E_{c i}(28)$ values obtained in the tested SFRSCC series, the $E_{c i}(t) / E_{c i}(28)$ function, evaluated according to the MC90 recommendation, is depicted in Fig. 6. This approach underestimates the elastic modulus at the ages of 3 and 7 days, and overestimates it at the age of $12 \mathrm{~h}$.

Fitting the parameters $a, b$ and $c$ of Eq. 4, the accuracy of the fitted curve increased considerably. The fitted curve parameters, as well as the $R^{2}$ value are indicated in Fig. 6.

The MC90 also proposes Eq. 5 for determining the relationship between the elasticity modulus, $E_{c i}$, and the average compressive strength, $f_{c m}$, in which, for plain concrete, $E_{c 0}=21.5 \mathrm{GPa}, f_{c m 0}=10 \mathrm{MPa}$ and $a=1 / 3$.

$E_{c i}=E_{c 0} \cdot\left(\frac{f_{c m}}{f_{c m 0}}\right)^{a}$

The relationship between the elasticity modulus and the compressive strength is depicted in Fig. 7. This figure also includes the analytical expression suggested by MC 90 and the one obtained by the non linear fitting procedure. Fitting parameters $E_{c 0}$ and $a$ increased substantially the adjustment of Eq. 5 towards the experimental data and, consequently, the correlation factor.

\subsubsection{Strain at peak stress}

For predicting the influence of concrete age on the strain at peak stress, $\varepsilon_{c 1}(t)$, was used the following hyperbolic function:

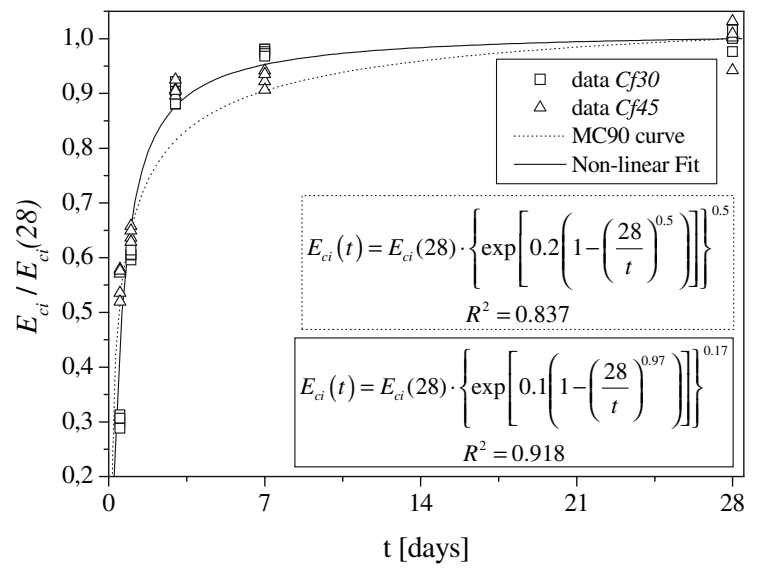

Fig. 6 Simulation of the age influence on the concrete elasticity modulus

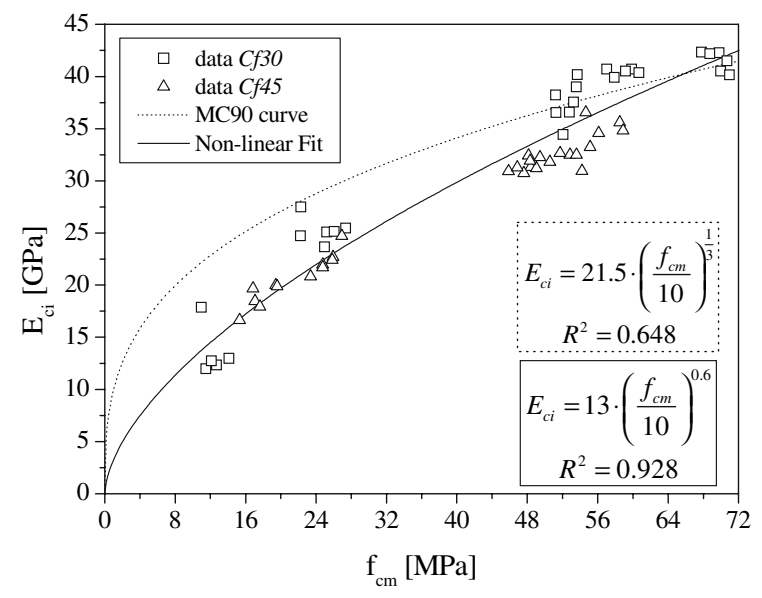

Fig. 7 Relationship between the concrete elasticity modulus and the compressive strength

$\varepsilon_{c 1}(t)=\frac{\varepsilon_{c 1}(28) \cdot \frac{t}{28}}{a+\frac{t}{28}}$

where $\varepsilon_{c 1}(28)$ is the strain at peak stress for the age of 28 days. This expression was adjusted to the experimental data by fitting the dimensionless parameter $a$.

The analytical relationship obtained by applying the fitting procedure to Eq. 6 is represented in Fig. 8. The quality of the adjustment of the previous equation is quite good. However, the obtained correlation factor is not too high. This is mainly due to the high scatter of the strain at peak stress observed for the age of $12 \mathrm{~h}$.

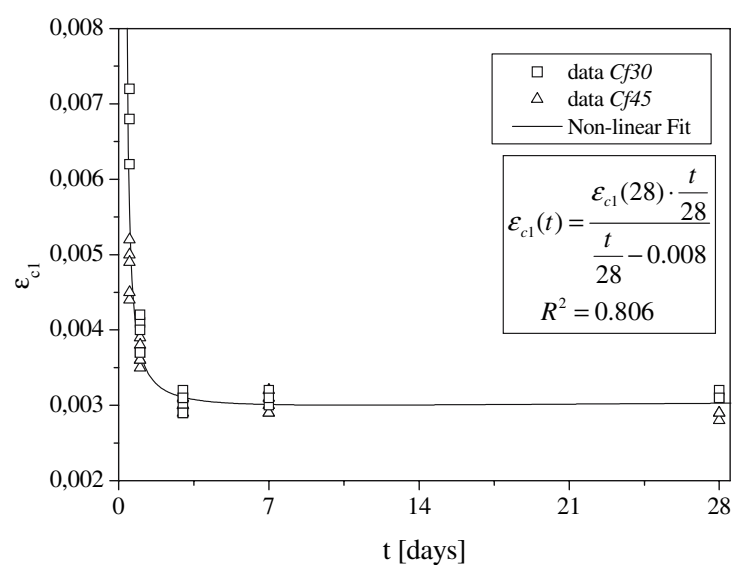

Fig. 8 Simulation of the age influence on the strain at peak stress 


\subsubsection{Energy dissipated under compression}

For the two tested series, the variance of the energy dissipated under compression, with respect to age, was distinct. To attain the relationship between the energy dissipated and age, $G_{c}(t)$, the following expression was used:

$G_{c}(t)=\frac{a \cdot t / 28}{b+t / 28}+\frac{c}{d+t / 28}+e \cdot \frac{t}{28}$

In both series a high scatter of $G_{c}(t)$ was observed, especially in the $C f 45$ series. The variation of $G_{c}$ with time, for both series, is depicted in Fig. 9. The values of the parameters $a, b, c, d$ and $e$ obtained in the fitting procedure are indicated in Fig. 9. The correlation factor was small, $R^{2}=0.589$, due to the high scatter observed.

\subsection{Stress-strain relationship}

The $\sigma_{c}-\varepsilon_{c}$ relationships available for modelling the compression behaviour of plain [7, 8] and fibre reinforced concrete $[9,10]$ cannot be directly applied to the developed SFRSCC, since the fitting degree they provide is not good enough. The main reason of this aspect is related to the distinct postpeak behaviours of plain and SFRSCC concretes. Therefore a new approach is proposed, to obtain an $\sigma_{c}-\varepsilon_{c}$ analytical expression that can predict the compression behaviour registered in the tested SFRSCC.

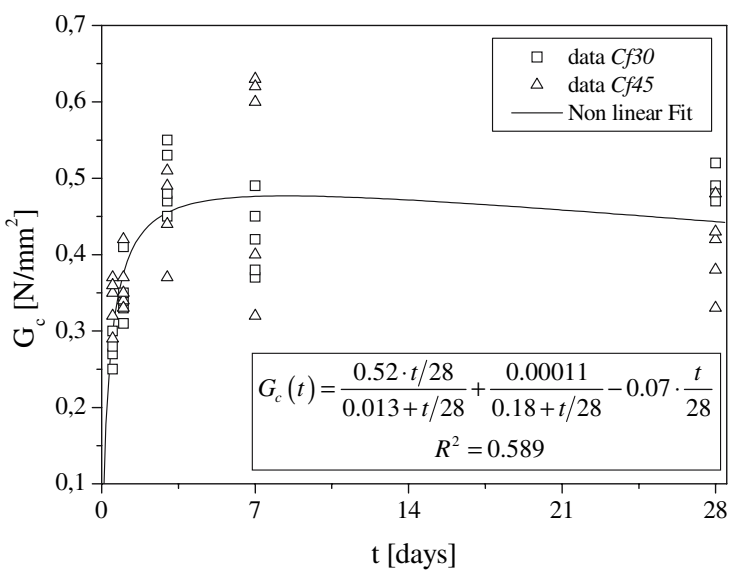

Fig. 9 Simulation of the age influence on the concrete energy dissipated under compression
The expression adopted in the present work is similar to the one proposed by the Model code 1990 (MC90) [8] for plain concrete, which is schematically represented in Fig. 10. In fact, the equation that corresponds to the branch represented by a straight line is the same one proposed by the MC90. For this branch, the stress-strain relationship is given by the following function:

$\sigma_{c}\left(\varepsilon_{c}\right)=\frac{\frac{E_{c i}}{E_{c 1}} \cdot \frac{\varepsilon_{c}}{\varepsilon_{c 1}}-\left(\frac{\varepsilon_{c}}{\varepsilon_{c 1}}\right)^{2}}{1+\left(\frac{E_{c i}}{E_{c 1}}-2\right) \cdot \frac{\varepsilon_{c}}{\varepsilon_{c 1}}} \cdot f_{c m} \quad$ for $\quad \varepsilon_{c} \leq \varepsilon_{c, \lim }$

where $E_{c i}$ and $E_{c 1}$ are, respectively, the tangent modulus and the secant modulus from the origin to the compressive strength, $E_{c 1}=f_{c m} / \varepsilon_{c 1} ; \sigma_{c}, \varepsilon_{c}$ and $\varepsilon_{c 1}$ are the compressive stress, the compressive strain and the strain at the compressive strength, respectively. The strain $\varepsilon_{c, \text { lim }}$ limits the applicability of Eq. 8 , see Fig. 10.

For the descending part of the stress-strain diagram, Eq. 8 is valid only for strain values up to $\varepsilon_{c, \text { lim. }}$. The strain $\varepsilon_{c, \lim }$ at $\sigma_{c, \lim } \quad\left(=\alpha \cdot f_{c m}\right)$ is computed from the following equation [18]:

$$
\begin{aligned}
& \varepsilon_{c, \lim }=\left[\frac{1}{2}\left[(1-\alpha) \cdot \frac{E_{c i}}{E_{c 1}}+2 \alpha\right]+\right. \\
& {\left.\left[\frac{1}{4}\left[(1-\alpha) \cdot \frac{E_{c i}}{E_{c 1}}+2 \alpha\right]^{2}-\alpha\right]^{0.5}\right] \varepsilon_{c 1} }
\end{aligned}
$$

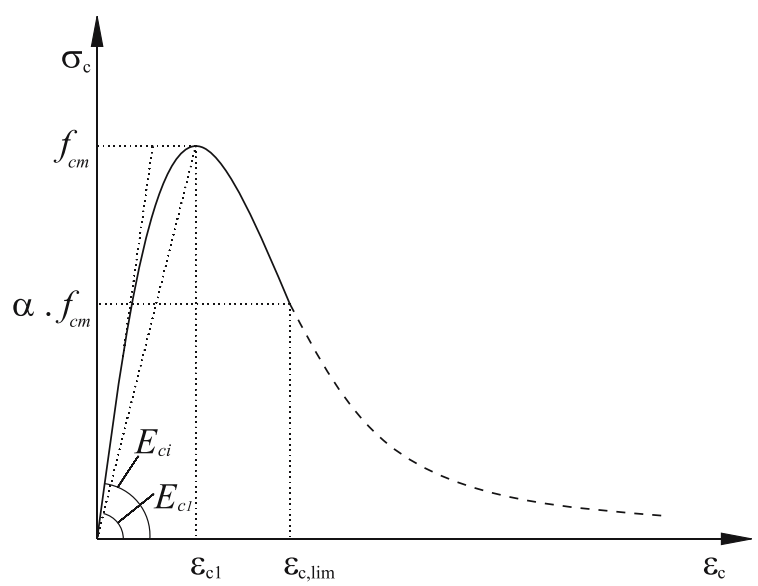

Fig. 10 Stress-strain diagram for uniaxial compression 
For $\varepsilon_{c}>\varepsilon_{c, \text { lim }}$ the descending branch of the $\sigma_{c}-\varepsilon_{c}$ diagram (dashed line in Fig. 10) is defined using an equation of the type:

$\sigma\left(\varepsilon_{c}\right)=\left[a\left(\frac{\varepsilon_{c}}{\varepsilon_{c 1}}\right)^{2}+b \frac{\varepsilon_{c}}{\varepsilon_{c 1}}\right]^{-1} \cdot f_{c m}$ for $\varepsilon_{c}>\varepsilon_{c, \text { lim }}$

where the values of parameters $a$ and $b$ are determined in order to assure the continuity of the function at the point $\varepsilon_{c}=\varepsilon_{c \text {,lim. }}$. Since the following conditions should be assured:

$\underbrace{\sigma_{c}\left(\varepsilon_{c, \lim }\right)}_{\text {equation (8) }}=\underbrace{\sigma_{c}\left(\varepsilon_{c, \lim }\right)}_{\text {equation (10) }} \wedge \underbrace{\left.\frac{\partial \sigma_{c}}{\partial \varepsilon_{c}}\right|_{\varepsilon_{c, \lim }}}_{\text {equation }(8)}=\underbrace{\left.\frac{\partial \sigma_{c}}{\partial \varepsilon_{c}}\right|_{\varepsilon_{c, \lim }}}_{\text {equation }(10)}$

Eq. 10 is converted into the following one:

$$
\begin{aligned}
& \sigma\left(\varepsilon_{c}\right)=\left[\left[\frac{1}{\frac{\varepsilon_{c, \lim }}{\varepsilon_{c 1}}} \xi \cdot\left(\frac{1}{2 \alpha}\right)^{2}-\frac{1}{\left(\frac{\varepsilon_{c, \lim }}{\varepsilon_{c 1}}\right)^{2}} \cdot \frac{1}{\alpha}\right]\left(\frac{\varepsilon_{c}}{\varepsilon_{c 1}}\right)^{2}\right. \\
& \left.+\left[\frac{1}{\varepsilon_{c, \text { lim }}} \cdot \frac{2}{\varepsilon_{c 1}}-\xi\left(\frac{1}{2 \alpha}\right)^{2}\right] \frac{\varepsilon_{c}}{\varepsilon_{c 1}}\right]^{-1} \cdot f_{c m}
\end{aligned}
$$

with

$\xi=\frac{4\left[\left(\frac{\varepsilon_{c, \lim }}{\varepsilon_{c 1}}\right)^{2} \cdot\left(\frac{E_{c i}}{E_{c 1}}-2\right)+2 \frac{\varepsilon_{c}}{\varepsilon_{c 1}}-\frac{E_{c i}}{E_{c 1}}\right]}{\left[\frac{\varepsilon_{c, \lim }}{\varepsilon_{c 1}}\left(\frac{E_{c i}}{E_{c 1}}-2\right)+1\right]^{2}}$

If $\alpha=0.5$, Eq. 9 and 12 become those proposed by the MC90.

In order to evaluate the applicability of the previous described relationship in the present experimental research, the following assumptions were taken: (a) the values of the elastic modulus, compressive strength and strain at peak-stress, used in the analytical simulation, were those obtained experimentally for each series; (b) the parameter $\alpha$ was adjusted in order to obtain the best fit of the analytical expression to the average stress-strain curve recorded experimentally.
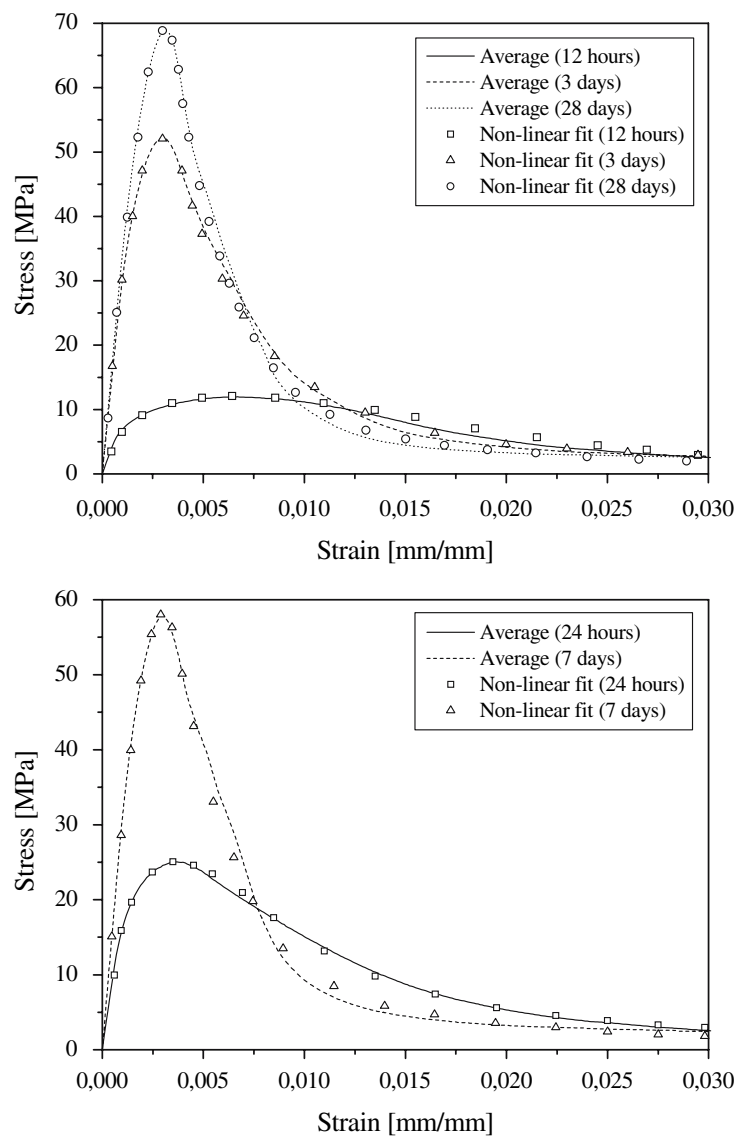

Fig. 11 Experimental and analytical relationships for $C f 30$ series

The analytical stress-strain curves obtained from the best fit procedure and the experimental average stress-strain curves are depicted in Figs. 11 and 12 for series $C f 30$ and $C f 45$, respectively. The accuracy of the proposed expression toward the experimental data is quite high.

Table 6 includes the values of the parameter $\alpha$ obtained in the non-linear fitting procedure. The $\alpha$ parameter increased with the age and tends to the limit value of 0.9 .

Figure 13 presents an exponential function used to estimate the evolution of the parameter $\alpha$ with the age. Additionally, the value suggested by MC90 for plain concrete is represented. Apart the $\alpha$ values of $C f 30$ series at $12 \mathrm{~h}$, the values of $\alpha$ obtained on the fitting procedure for the developed SFRSCC are higher than the value proposed by MC90 for plain 

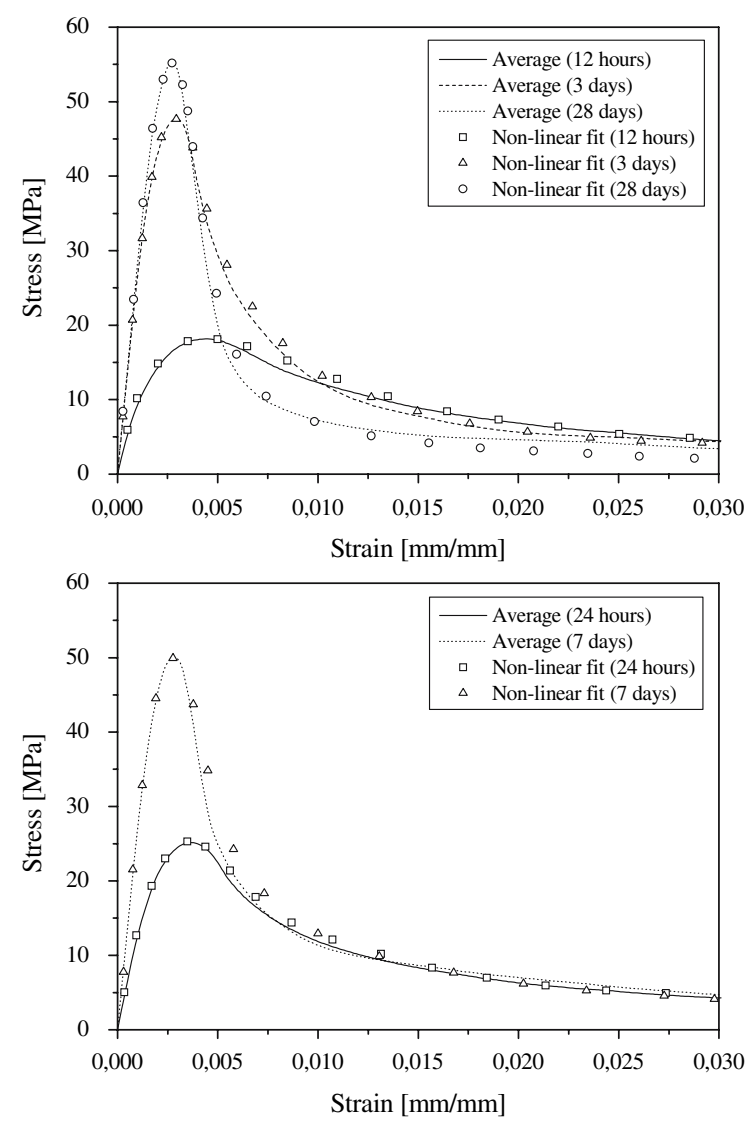

Fig. 12 Experimental and analytical relationships for $C f 45$ series

concrete. The correlation factor $R^{2}$ obtained was 0.797 and the expression is the following one:

$\alpha(t)=0.9 \cdot \exp \left\{0.005\left[1-\left(\frac{28}{t}\right)^{1.16}\right]\right\}$

Due to the distinct compressive strengths for the series $C f 30$ and $C f 45$ at the same age, and considering that the compressive strength influences significantly the shape of stress-strain curve, better results are attained relating the parameter $\alpha$ with the compressive strength. In Fig. 14 is presented the exponential

Table 6 Values of parameter $\alpha$ obtained from the non-linear fitting procedure

\begin{tabular}{cccccc}
\hline Age & $12 \mathrm{~h}$ & $24 \mathrm{~h}$ & $3 \mathrm{~d}$ & $7 \mathrm{~d}$ & $28 \mathrm{~d}$ \\
\hline$C f 30$ & 0.423 & 0.657 & 0.839 & 0.871 & 0.889 \\
$C f 45$ & 0.675 & 0.776 & 0.876 & 0.890 & 0.860 \\
\hline
\end{tabular}

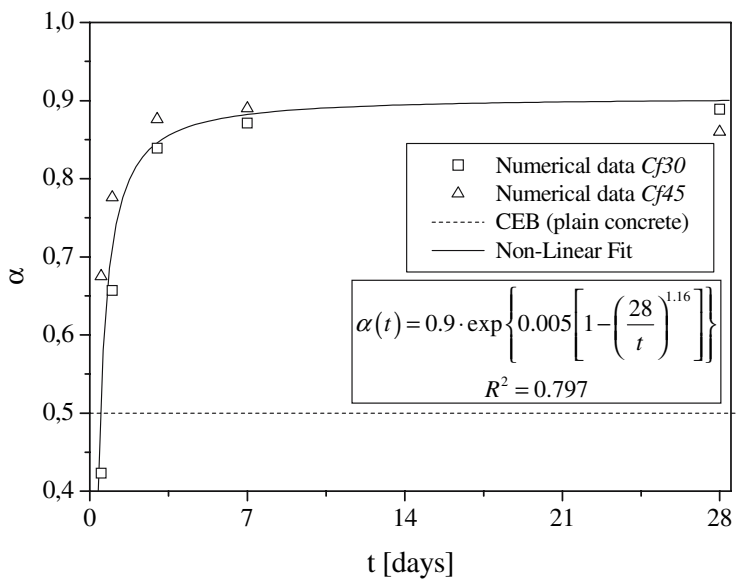

Fig. 13 Relationship between parameter $\alpha$ and age

function used to estimate the evolution of the parameter $\alpha$ with the compressive strength:

$\alpha(t)=0.87 \cdot \exp \left\{0.04\left[1-\left(\frac{f_{c m, 28}}{f_{c m}(t)}\right)^{1.8}\right]\right\}$

The degree of accuracy increased significantly. The value of correlation factor is 0.938 . Note that $f_{c m}(t)$ can be estimated from the expression indicated in Fig. 5.

\section{Conclusions}

An experimental programme was carried out to evaluate the influence of the concrete age and fibre content on the compressive behaviour of steel fibre reinforced self-compacting concrete, SFRSCC.

The main mechanical properties of the SFRSCC, such as: compressive strength, $f_{c m}$, elasticity modulus, $E_{c i}$, strain at peak stress, $\varepsilon_{c 1}$ and the volumetric dissipated energy, $G_{c}$, were assessed for the ages of 12 h, 24 h, 3, 7 and 28 days. Two distinct contents of fibres were considered, $30 \mathrm{~kg} / \mathrm{m}^{3}$ and $45 \mathrm{~kg} / \mathrm{m}^{3}$.

The compressive strength, as well as the elasticity modulus increased with age, mainly in the recent ages, i.e. until the 3 days. Increasing the fibre content from $30 \mathrm{~kg} / \mathrm{m}^{3}$ to $45 \mathrm{~kg} / \mathrm{m}^{3}$ has, in general, lead to a decrease of the $f_{c m}$ and $E_{c i}$ values. This might be due to the different curing temperatures for the two series, and the higher limestone filler content for the series with $45 \mathrm{~kg} / \mathrm{m}^{3}$ of fibres. For 


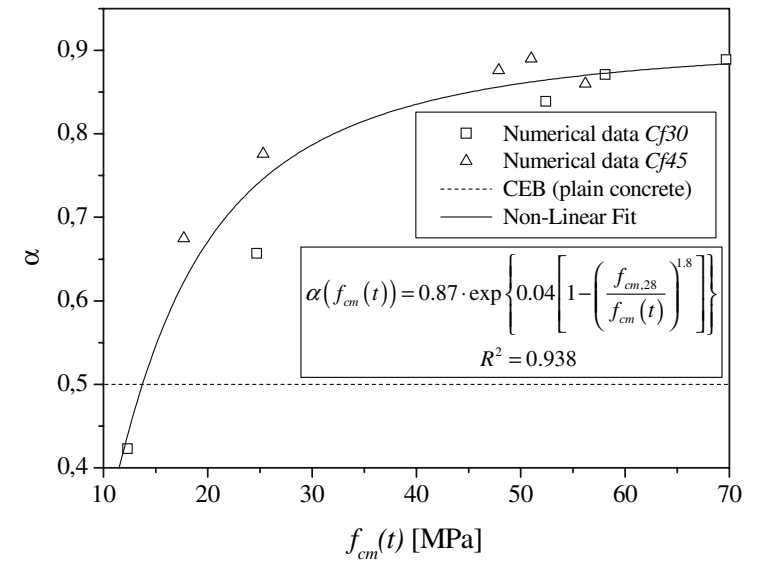

Fig. 14 Relationship between parameter $\alpha$ and compressive strength

the latter series, it was necessary to incorporate higher concentrations of fine particles (e.g. limestone filler), in order to attain high flowability and high segregation resistance.

The strain at peak stress decreased with the age for both series of distinct fibres contents, as a consequence of the matrix stiffness increase with the age. The value obtained experimentally, for the 28 days, was similar to the values obtained by several authors for current steel fibre reinforced concrete. In general, the energy dissipated under compression increased with the age. However, it was not observed a significant change with the increment of the fibre content, from $30 \mathrm{~kg} / \mathrm{m}^{3}$ to $45 \mathrm{~kg} / \mathrm{m}^{3}$ for the older ages. This might be due to the higher content of filler for the $C f 45$ series, which increased the brittleness of the fibre interfacial transition zone, and as a consequence, the fibres reinforcement mechanisms become less effective. In general the energy absorption capacity was directly dependent on the SFRSCC compressive strength.

Analytical expressions to predict the most significant mechanical properties of the developed SFRSCC at an age $t$ were presented. A stress-strain relationship was proposed to model the behaviour of the SFRSCC since the early ages. This relation was capable of modelling the complete compressive behaviour of SFRSCC with high accuracy.

Acknowledgements The study reported in this paper is part of the research program "Prefabricated sandwich steel fibre reinforced panels"' supported by FEDER and MCT, and promoted by ADI (the funds were $45 \%$ of the applied amount). This project involves the Companies PREGAIA and CIVITEST, and the University of Minho. The authors wish to acknowledge the materials generously supplied by Bekaert (fibers), SECIL (cement), Degussa (superplasticizer), and Comital (limestone filler). The first author wishes also to acknowledge the grant SFRH/BD/18002/2004, provided by FCT.

\section{References}

1. Balaguru PN, Shah SP (1992) Fiber reinforced cement composites. McGraw-Hill Inc, New York

2. Casanova P (1996) Steel fibre reinforced concrete: from the material to the structure. Ph.D. thesis, Ecole nationale des Ponts et Chaussées (in French)

3. ACI 544-1R., State-of-the-art report on fiber rein-forced concrete. Technical report, American Concrete Institute, 1997

4. Rosenbusch J, Teutsch M (2003) Shear design with method, test and design methods for steel fibre reinforced concrete-Background and experiences. In:Schnutgen B, Vandewalle L(eds), RILEM publication PRO 31:105-118

5. Kodur VKR, Bisby LA (2005) Evaluation of fire endurance of concrete slabs reinforced with fibre-reinforced polymer bars. J Struct Eng 131(1):34-43

6. Grünewald S (2004) Performance-based design of selfcompacting fibre reinforced concrete. Ph.D. thesis, TU Delft, Netherland

7. Carreira DJ, Chu KH (1985) Stress-strain relationship for plain concrete in compression. ACI J 82(6):797-804

8. CEB-FIP (1993) CEB-FIP Model Code 1990: Design code. Thomas Telford, Lausanne

9. Ezeldin AS, Balaguru PN (1992) Normal and high strength fibre reinforced concrete under compression. J Mater Civil Eng 4(4):415-427

10. Hsu LS, Hsu CT (1994) Stress-strain behaviour of steelfibre high strength concrete. ACI Struct J 91(4):448-457

11. Pereira EB, Barros JAO, Cunha VMCF, Santos SPF (2005) Compression and bending behaviour of steel fibre reinforced self-compacting concrete. ConMat'05 and Mindess Symposium. In: Banthia N, Uomoto T, Bentur A, Shah SP (eds) Vancouver, p 10

12. LNEC E397 (1993) Concrete-Assessment of the elasticity modulus under uniaxial compression. Laboratório Nacional de Engenharia Civil, (in Portuguese).

13. Barros JAO (1995) Behaviour of fibre reinforced concrete, experimental and numerical analysis. Ph.D. thesis, Faculdade de Engenharia da Universidade do Porto, Portugal (in Portuguese)

14. Schindler AK (2004) Effect of temperature on hydration of cementicious materials. ACI Mater J 101(1):72-81

15. Poppe A-M, de Schutter G (2005) Cement hydration in the presence of high filler contents. Cement Concrete Res 35:2290-2299

16. Kooiman AG (2000) Modelling steel fibre reinforced concrete for structural design. Ph.D. thesis, TU Delft, Netherlands 
17. EN 1992-1-1 (2004) Eurocode 2: Design of concrete structures-Part 1-1: General rules and rules for buildings. European Committee for Standardization, Brussels

18. Cunha VMCF, Barros JAO, Sena-Cruz JM (2006) Compression behaviour of steel fibre reinforced concrete (age influence and modelling). Technical report no. 06-DEC/
E-04, Department of Civil Engineering, University of Minho, 49 pp., (URL: http://www.civil.uminho.pt/ composites/Publications/2006/TR2006_001_06_DEC-E04.pdf) 